series of dazzling thought experiments aided by cameos from Shannon and philosophers Spinoza, Leibniz and Thomas Nagel (the only living person to figure in the book). Through them, Galileo understands how the algebra of integrated information is turned into the geometry of conscious experiences, and how this links to the physiology and the anatomy of the brain.

In the book's final third, Tononi lays out the implications of his theory. He discusses a number of points about consciousness: that it ceases in death and dementia, does not require language or knowledge of self, exists in animals in graded forms and can be present, to some degree, in the fetus.

Hell, Tononi emphasizes, is all in the mind. One of the most chilling characters in Phi is the Master, an amalgam of the captain in Franz Kafka's 1914 short story In the Penal Colony and the Grand Inquisitor from Fyodor Dostoyevsky's novel The Brothers Karamazov (1880). The

Master's obsession

"This is a story for grown men, not a consoling tale for children." is creating perfect never-ending pain by manipulating the brain's informational content. In the final chapter, the Mannequin, a stand-in for Mephistopheles, throws up some logical paradoxes before leaving the dying Galileo reunited with his beloved daughter.

$P h i$ is extraordinary. In its appeal to the imagination, it bears some resemblance to Edwin Abbott's Flatland novella (1884) or Douglas Hofstadter's Gödel, Escher, Bach (Basic Books, 1979). Yet its language is more poetic, and full of cultural references and images - film stills and often modified coloured photos of artworks. Endnotes to each chapter link the allegories and metaphors in the text to the science.

I believe that in the fullness of time, the quantitative framework outlined in $\mathrm{Phi}$ will prove to be correct. Consciousness is tightly linked to complexity and to information, with profound consequences for understanding our place in the evolving Universe. As Crick says to Galileo, this is a "story for grown men, not a consoling tale for children".

Christof Koch is chief scientific officer at the Allen Institute for Brain Science in Seattle, Washington, and professor of biology and engineering at the California Institute of Technology in Pasadena, California.

e-mail:christofk@alleninstitute.org

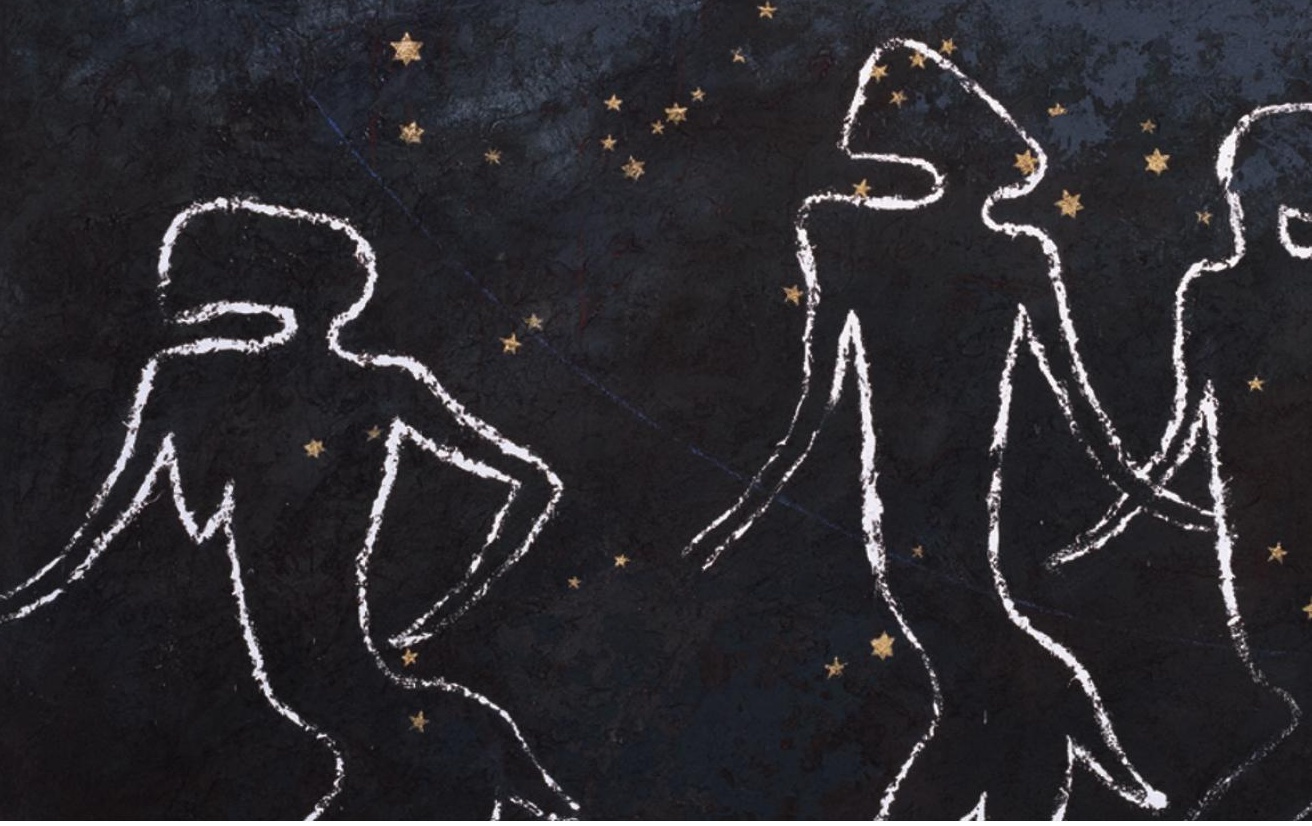

Gavin Jantjes' untitled painting depicts a Khoisan girl creating the Milky Way.

\title{
ASTRONOMY
}

\section{Under African skies}

\section{Ivan Semeniuk follows the gaze of artists from cultures that have interpreted the heavens for millennia.}

$\checkmark$ azing up at a sky full of stars is one of the most universal of human experiences, cutting across cultures and, one imagines, stretching back to the dawn of humanity. Yet artistic depictions of the heavens in popular culture are predominantly European - from Johann Bayer's engravings of the constellations in his 1603 star atlas Uranometria to the swirling brilliance of Van Gogh's 1889 painting The Starry Night.

An exhibition at the US National Museum of African Art, part of the Smithsonian Institution in Washington DC, may help to change that. It showcases a range of contemporary and historical pieces by African artists. All are connected in one way or another to the Sun, Moon or stars.

African Cosmos: Stellar Arts was sponsored in large part by the government of South Africa.

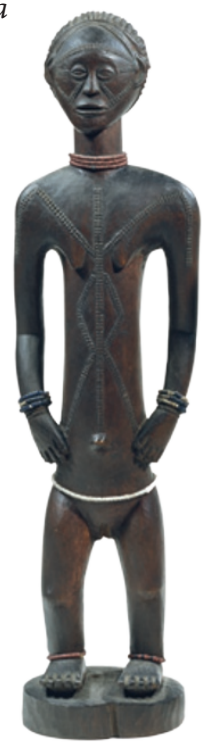

The country was selected this year, along with Australia, to host the Square Kilometre Array, which will be the world's largest radio telescope; that association adds to the sense of interplay between the scientific and the spiritual that weaves its way through the exhibition. The show seamlessly bridges the centuries, uniting pieces as diverse as traditional moon masks from Côte d'Ivoire and Trembling Field, an interactive sculpture by South African Karel Nel. Nel is resident artist with the Cosmic Evolution Survey, a project that focuses on a two-square-degree field of the sky to see how the Universe has changed over time.

"Africa has a long and rich history of keen observation of the heavens," says the exhibition's curator, Christine Mullen Kreamer. "Works

Figures from Central Africa bear lunar patterns. 
of art can allows us access to that history, and that knowledge."

The journey begins on territory that is both ancient and familiar, with a series of pieces from pharaonic Egypt. Representations of cosmic deities and celestial objects such as the bright star Sirius are reminders of the night sky's prominent role in the rituals and beliefs of civilizations along the Nile. The exhibition goes on to leap across the Sahara and forward in time. Far more exotic to non-African eyes are items that date back only a century or so: a bowl and lid from Nigeria representing the domains of Earth and sky, or a Dogon stool from Mali, which depicts human ancestral figures descending from the heavens to populate the land below.

One of the more striking of the contemporary works, an untitled painting by South African artist Gavin Jantjes, playfully reverses the theme of genesis from above. Based on a Khoisan myth from southern Africa, it depicts the story of a girl dancing around a fire. She throws glowing embers high into the night, thereby creating the Milky Way, the dominant feature of the southern sky.

So might the creative sparks tossed skywards from such an exhibition serve to illuminate a continent's worth of artistic achievement and potential.

Ivan Semeniuk is Nature's chief of correspondents in Washington.

\section{Books in brief}

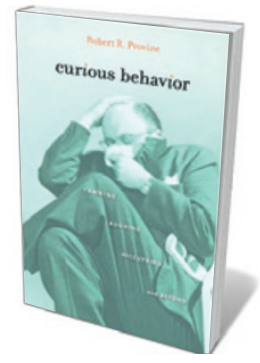

Curious Behavior: Yawning, Laughing, Hiccupping, and Beyond Robert R. Provine HARVARD UNIVERSITY PRESS 246 pp. £18.95 (2012) How can farting, sneezing and other marginal biological realities illuminate humanness? Neuroscientist Robert Provine turns an evolutionary lens on everything from the gross to the faintly improper. The 'contagiousness' of yawning, for instance, hints at the roots of empathy and herd behaviour. Burping and farting were involved in the development of speech, says Provine. And tickling may play a part in our early understanding that we are distinct beings (you can't tickle yourself). An exercise in 'small science' some of it speculative, all of it fascinating.

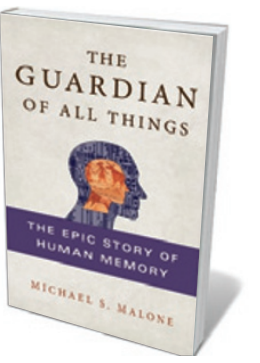

The Guardian of All Things: The Epic Story of Human Memory Michael S. Malone ST MARTIN'S PRESS 304 pp. £18.99 (2012) Memory is a kind of relay, with each generation passing its torch on to the next — creating a conduit for thought and civilization through the eons. In his evocative book, technology writer Michael Malone traces that history from the brain's evolution and the development of speech and writing to advances in recording, the rise of technology and the shifts in ownership of memory from the tribal elect to the masses. The book is packed with gems, including a passage on the twelfth century, when Greek and Arabic science infused Europe, filling its libraries and helping to seed its universities.

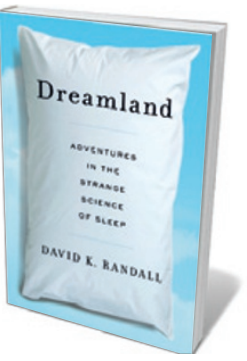

\section{Dreamland: Adventures in the Strange Science of Sleep}

David K. Randall NORTON 304 pp. £17.99 (2012)

Sleep occupies us for one-third of our lives. So insomnia, nightmares, deprivation and other aspects of bad sleeping are an obsession for thousands. The tipping point for journalist David Randall was sleepwalking into a wall. Astonished by a specialist's admission of ignorance about the condition, Randall set out to uncover research and shine a light into some dark corners. The entertaining result covers plenty of territory, from the medieval habit of dividing nightly sleeps to the link between vacuum cleaners and sleep apnea. Along the way, Randall picks up the basics for crafting a healthy snooze.

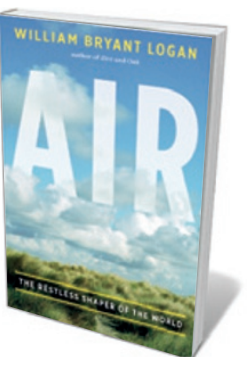

\section{Air: The Restless Shaper of the World}

William Bryant Logan NORTON 416 pp. £13.99 (2012)

Arboriculturist William Bryant Logan follows Oak (Norton, 2005) and Dirt (Norton, 2007) with this splendid exploration of the "floating world" of air - our planet's invisible skin. Starting with the tornadoes that hit New York in 2010, he both warns of and celebrates the often turbulent and dangerous action of atmosphere. Logan delivers vast amounts of science with brevity and elegance, and is as breezy describing the billion tonnes of dust that blow from African deserts to fertilize the Amazon as he is discussing the echolocation skills of some people with sight impairment.

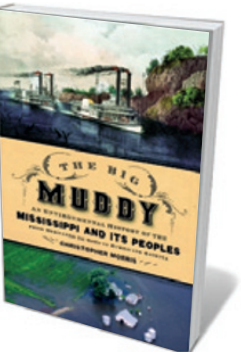

The Big Muddy: An Environmental History of the Mississippi and Its Peoples, from Hernando de Soto to Hurricane Katrina Christopher Morris OXFORD UNIVERSITY PRESS 336 pp. £22.50 (2012) Seven years ago this month, Hurricane Katrina triggered massive flooding in the valley of the Mississippi. The environmental backstory of the catastrophe is as rich as river sediment, and historian Christopher Morris takes us through 500 years of it. The valley's metamorphosis from vast wetland staked out by France and Spain to a patchwork of development - drained swamp, levees, deforestation, industry and poor urban planning — is powerfully recounted. 